\title{
Situating the Research to Practice Cycle For Increased Transformation in Engineering Education
}

\section{Dr. Jennifer Karlin, South Dakota School of Mines and Technology}

Jennifer Karlin is an professor of industrial engineering at the South Dakota School of Mines and Technology and holds the Pietz Professorship for entrepreneurship and economic development.

\section{Dr. Cheryl Allendoerfer, University of Washington}

Dr. Allendoerfer is a Research Scientist in the College of Engineering at the University of Washington.

\section{Prof. Rebecca A Bates, Minnesota State University, Mankato}

Rebecca A. Bates received the Ph.D. degree in electrical engineering from the University of Washington in 2004. She also received the M.T.S. degree from Harvard Divinity School in 1993. She is currently a Professor in the Department of Integrated Engineering program at Minnesota State University, Mankato, home of the Iron Range and Twin Cities Engineering programs. She is also a program director at the National Science Foundation for TCUP and HBCU-UP in the Division of Human Resource Development.

\section{Dr. Dan Ewert, North Dakota State University}

Dr. Ewert has been involved in cardiovascular engineering for over 25 years in both research and instruction. He has consulted for major medical device companies in the area of cardiovascular engineering and performed research with US and international colleagues. He has a broad background in mechanical and electrical engineering, and physiology with specific training and expertise. His work includes modeling the cardiovascular system, ventricular assist devices, cardiac physiology, instrumentation systems and leadless cardiac pacing. He help developed and was the inaugural director of a project-based-learning engineering curriculum. He is now involved in discovery-based-learning on multi-disciplinary teams.

\section{Mr. Ronald R Ulseth, Itasca Community College}

Ron Ulseth directs and instructs in the Iron Range Engineering program in Virginia, Minnesota and he teaches in the Itasca Community College engineering program in Grand Rapids, MN. He was instrumental in growing the Itasca program from 10 students in 1992 to 160 students in 2010. In 2009, he worked with a national development team of engineering educators to develop the 100\% PBL curriculum used in the Iron Range model. He has successfully acquired and managed over $\$ 10$ million in educational grants including as PI on 7 grants from NSF. He has been in the classroom, teaching more than 20 credits per year to engineering students for more than 25 years. His specific areas of expertise are in active learning, faculty development, and learning community development. He has been awarded the 2012 Progress Minnesota award, 2012 Labovitz Entrepreneurialism award, and 2012 Innovator of the Year award from the Rural Community College Alliance all for his work in developing the Iron Range Engineering program. His degrees are in civil engineering (B.S., University of North Dakota), and mechanical engineering (M.S., University of Central Florida). He is licensed as a professional engineer in the state of Minnesota. 


\title{
Situating the Research to Practice Cycle for Increased Transformation in Engineering Education
}

\begin{abstract}
The educational research to educational practice cycle is an important framework for connecting the fundamental research in engineering education to the real world of the classroom and other learning environments. When applied consistently, the educational research to practice cycle bonds the two halves by elucidating new questions from practice and finding new answers through research, which is then applied in practice. Ideally, the educational researchers are grounded in the needs and changing context of the practitioner and the educational practitioner is using evidence from the research as a key component in their pedagogical decision making. While we have seen some gains through this model, large-scale, systemic transformation has been largely elusive. This paper situates the research to practice cycle in the organizational context to illustrate key barriers to transforming engineering education.

This paper is designed to start a conversation within the engineering education discipline about how better situating this model in organizational structure and organizational change can make the research to practice cycle in engineering education more effective. It will define organizational structure and barriers to organizational change within the context of the research to practice cycle, including how organizational infrastructure allows researchers to craft evidence-based implementations that are more likely to succeed in a particular location and to identify a set of initial potential barriers to success. Awareness of the, often unintended, messages that the organizational infrastructure sends are an important part of managing change in our educational practices and discovering under-studied areas of engineering education. This paper also ties to on-going work by the authors to examine specific implementations of engineering education transformation and identify mechanisms to overcome organizational and systemic barriers to evidence-based changes in engineering education practice.
\end{abstract}

\section{Introduction}

In his 2008 report to the National Academies, James Fairweather ${ }^{1}$ wrote:

Not surprisingly the primary reform effort in undergraduate STEM education, whether funded by the external agencies such as the NSF or by individual institutions, has been at the classroom level particularly through the use of more effective pedagogical practices and a conceptual shift from teacher- to learnercenteredness. Most of the papers presented at the two NAS workshops focus on teaching and learning in the classroom as have most of the NSF-funded projects through its course and curriculum development (CCLI) program. Most university efforts to improve teaching and learning likewise focus on 3 (voluntary) professional development programs for individual faculty members (Wulff \& Austin, 2004). Yet this broad agreement on "the problem" and the trend to focus on improving individual classroom instruction has not led to a more seasoned understanding of the root causes of ineffective teaching and learning, low retention in the major and the declining pool of American students entering into STEM doctoral programs. 
In the years since this report, we have continued to improve our understanding of engineering education, yet the practices described by Fairweather have largely not changed. Studies have consistently found awareness of research-based instructional practices to be high among engineering faculty ( $80 \%$ or more aware $)^{2,3}$, yet faculty behavior change remains low, ranging from 5 to 65 percent for examined practices ${ }^{3}$. This is particularly jarring given that changing faculty instructional behaviors are necessary to broadly reap the potential of the changes in engineering education that occurred over the past decades ${ }^{4}$.

How, then, do we transfer knowledge both within the engineering education practitioner community and between engineering and society? How do we transfer both the content knowledge of engineering and the process knowledge of engineering education? Many engineering faculty, and much of the research, discuss this interface as occurring in classrooms and other formal education opportunities. Considering only formal education is limiting to our understanding of the practice of engineering education and the impact of engineers on society; founding axioms, as discussed below, are a recurring theme in the translation of technical literacy. Jesiek et al. ${ }^{5}$ show the increasing use of the various models to discuss the connections between research and practice, including Stokes' research quadrants ${ }^{6}$ and the more familiar research to practice cycle as adapted for and by the National Science Foundation during the time of the Course, Curriculum, and Laboratory Improvement (CCLI) program ${ }^{7}$. The use of the research-to-practice cycles, while an encouraging development, has not made a large enough change in the ways engineering education researchers think about framing their results for use across the broad varieties of practices. We posit that the common understanding of the researchto-practice model is one of impeding factors and that resituating the research-to-practice model is a necessary, though not sufficient, step towards transforming engineering education practice. The objective of this paper is to examine the limitations of the current research to practice cycle and expand the conversation to include a broader and more nuanced understanding of why sustainable change in engineering education has not yet happened at a systemic level.

\section{Research to Practice Cycle}

The research to practice cycles tend to look like that used in the CCLI program description ${ }^{7}$, Figure 1, or the "Innovation Cycle of Educational Practice and Research" adapted from Booth, Colomb, and Williams ${ }^{8}$ and proposed by the American Society for Engineering Education ${ }^{9}$, Figure 2. These cycles share several aspects important to the continued transformation of engineering education, including:

- one of the (often unspoken) goals of research in engineering education is to improve practice in engineering education; and

- engineering education practice is a key course of questions to be answered through engineering education research. 


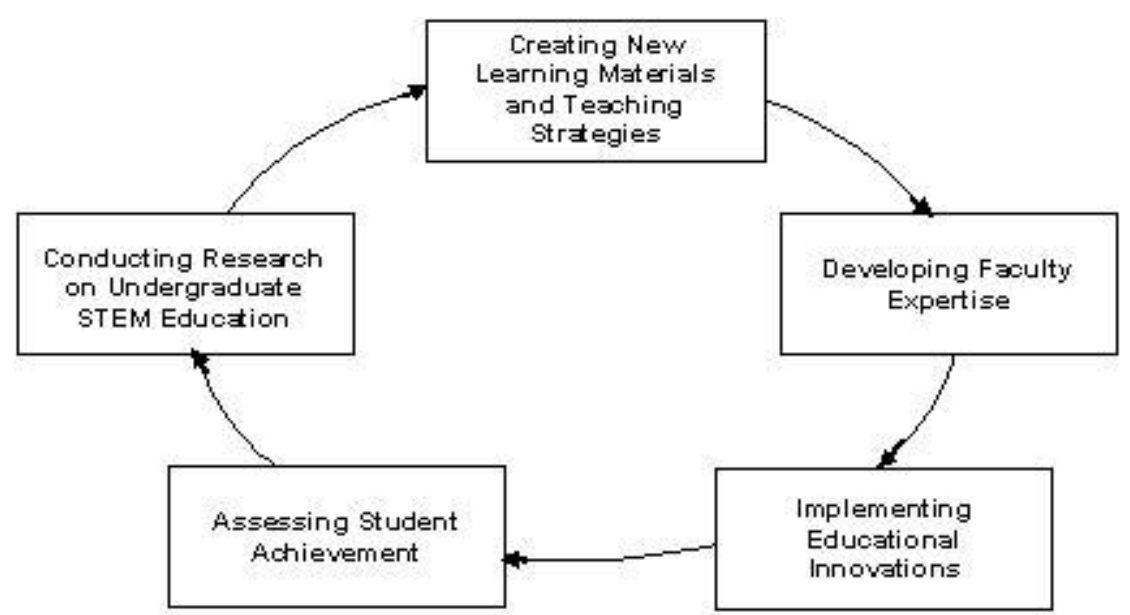

Figure 1. Cycle of STEM Education Research and Implementation ${ }^{7}$

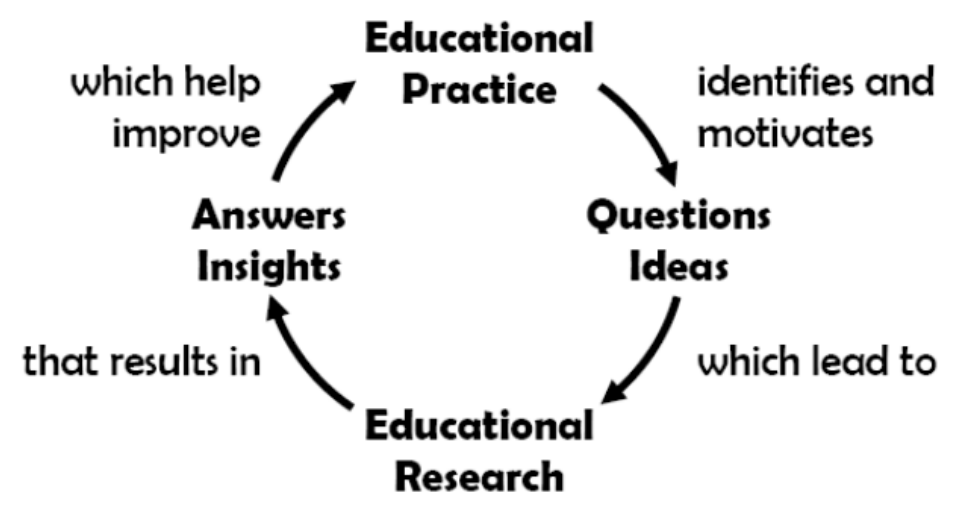

Adapted from Booth, Colomb, and Williams, 2008

Figure 2. The Innovation Cycle of Educational Practice and Research ${ }^{9}$

While these recognitions are vital to our understanding of the connection between research and practice, without a better understanding of what additional elements are impeding change, we are unlikely to see transformation at scale or with sustainability. We propose that two of the core areas that need to be considered in the framing of the research to practice cycle are the organizational context in which the practice occurs and the founding axioms of the researchers and practitioners. From this theoretical background, we then build a second generation research to practice cycle.

\section{Organizational Context}

Some of the barriers not illustrated in the current research to practice models are embedded in the culture and infrastructure of the organization. An organization's culture is a set of assumptions and beliefs that are so ingrained in members of the organization that they, knowingly or not, consistently reinforce or punish related behaviors ${ }^{10,11}$. The organizational infrastructure, then, is the set of systems, policies and procedures, and pathways that connect people, goals, and information. In both engineering education research and practice, this includes both local and discipline-wide concerns. Local concerns include college/university workload models, 
departmental resource allocation, and the ability to interact with engineering education researchers and evidence-based practitioners at one's own institution. Discipline-wide concerns include the availability of journals and conferences for publishing engineering education research (both for those publishing new results and those looking for solutions), the allocation of funding for engineering education research as well as curricular transformation, and the ability to connect with potential partners for engineering research and/or practice at other institutions. Both organizational culture and infrastructure are tied to an individual's performance and daily behaviors $^{12}$.

There are two primary organizational contexts in which we must situate the research to practice cycle: organizational structure and barriers to organizational change. The organizational structure includes the tacit or explicit hierarchy of faculty, departments, colleges, accreditation bodies, and core systems such as the registrar and financial aid. Each of the groups, and sometimes subgroups within them, bring their own founding axioms, or assumptions and ways of thinking. In order to have large-scale, sustainable change, we must bridge these groups together and help them learn to dialogue. An example of structure as a barrier to transformation is the reliance on the credit hour at many colleges and universities not only to describe curriculum and student progress, but also to ensure compliance with financial aid, graduation requirements, and accreditation. Leveraging change management models illustrates additional barriers, such as concerns for future competence and perceived loss of power. Situating the research to practice cycle in the reality of organizational structure and change sheds light on the potential barriers we need to overcome to create lasting, positive change in engineering education.

In order to see real, sustainable improvement in engineering education practice, we must have positive change in both the behaviors of the participants and the systems within which these participants act. This structure of change follows the dual core model posited by Daft ${ }^{13}$, where the two cores are the technical and the administrative. The technical core consists of the operations level activities of the organization, which for engineering education includes the decision making processes and actual education practices employed by instructors. The administrative core includes the structure, culture and climate, and policies and procedures that influence, and sometimes direct, the operations of the organization. Changes in the technical core alone are unlikely to persist, though changes in the administrative core lead to changes in the

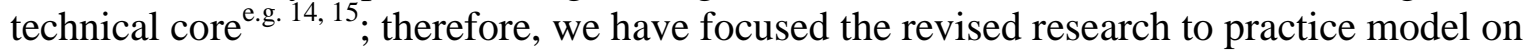
understanding the activities of individuals during an administrative change. Further, this process highlights the importance of how change agents work with the differing groups, or sub-cultures, within the university as well as the opportunity for leadership from the faculty and department chair ranks.

The organizational change necessary to build healthy, functional universities that encourage innovations in engineering education is most often thought of as either push from the top down or collectively rallied from the bottom up ${ }^{\text {e.g., } 16,17}$. Another reason for focusing on the administrative core is that neither concept fully explains the importance of sub-cultures as well other barriers to sustainable organizational change, such as the processes and effort necessary to shift an organizational culture and the potential pathways to build that momentum, particularly in larger organizations. 
An organizational sub-group that "demonstrates the culture and traits of a learning organization" is called a learning pocket ${ }^{18}$. These learning pockets illustrate the third path for organizational change mentioned above: leading from the middle. Managers and faculty who form strong, healthy organizational cultures within their workgroups or units and then participate in the movement of these cultural variables from the sub-culture to the dominate culture are creating change at the whole-organization level. The diffusion of the "storehouse of pooled learning" and "the set of standardized orientations to recurrent problems ${ }^{19}$ " of a learning pocket or a network of learning pockets to the dominant culture is a mechanism for improving the entire organization.

\section{Founding Axioms}

The environment in which the change is occurring and administrative and political structures necessary for that change to be sustainable is multi-faceted and includes key players from different silos within the university and in the larger community. The systemic barriers to implementing, sustaining, and credentialing innovative engineering education practices are seen in our previous work ${ }^{20}$ as well as Kolmos and de Graaff's summary of institutional change in higher education $^{21}$. Our key theoretical frameworks are the founding axioms of the change constituents and the mechanisms of organizational change necessary to unite these axioms for sustainable, systemic improvement.

Most engineering educators want the same thing - students who have learned the material well because most educators desire to educate the best engineer. If this is a common goal, then why are changes in engineering education often associated with difficulties and strife? What is presented next is a framework for understanding why well-intentioned educators with the same goal can often fail to consider and/or adopt change to engineering education practices.

An axiom is a starting assumption, postulate, or belief taken to be "true" - "self-evident" truth. Starting from axioms, organized and logical systems of thought can be developed using logic, additional beliefs, and assumptions. These systems of thought are the basis of social organizations whether educational, political, religious, or scientific. Thought systems are usually internally consistent. In other words, they "make sense" and "are obvious" to those immersed in that system's culture. But when viewed by someone from another system of thought, the ideas that "make sense" and "are obvious" in one thought system might not be sensible or obvious at all to someone from another thought system.

Perhaps a way to understand this situation is by example. Mathematics is a field of systematic inquiry based on axioms. One starts from a set of axioms and derives a system of relations using logic. Euclidean geometry starts with five axioms and from these are derived the rich set of planar geometric rules ${ }^{22}$. A simple rule that emerges from this thought system is that the shortest distance between two points is a straight line in planar geometry. Euclid's fifth axiom is often called the parallel postulate because it results in two parallel lines never intersecting. Others believed that one could alter the fifth postulate and in changing just this one axiom, a new set of geometric rules were derived for curved space ${ }^{23}$. Simplistically, on a sphere, the shortest distance between two points is not a straight line, but a great circle.

In this example, two thought systems based on the same four axioms, but a different fifth axiom, resulted in two very different geometric systems with different conclusions about the shortest 
distance. These thought systems each have internally consistent views, but with a view of the world unrecognizable to the other (i.e., the shortest distance between two points). This simplistic example represents a best case scenario in trans-thought system communication difficulties. This is a best-case scenario because four of five axioms are the same, and mathematics is a highly disciplined field with well-defined rules, where logic and reason prevail. Imagine how much more difficult the trans-thought system communication is when the axioms of two thought systems are entirely different, where the derivation rules are ill-defined or different, and less logic and more emotion are used in the development of the thought system. The point is that communication can be difficult across thought system boundaries based on even simple axiomatic changes in a highly structured field.

We return to the idea that most educators have a common goal, students who have learned the material well. When changes to improve our achievement of that goal are proposed (thought system 1), that idea must be communicated to others (thought system 2). By way of an educational example, one axiom of thought system 1 might be stated as, "students need to solve textbook problems 40 hours/week to be good engineers." In thought system 2, an axiom might be stated as, "contextual experiential learning is the best way educate an engineer." When communication across these two systems is attempted without regard to the underlying axioms, there is little hope of securing change. To make matters even more difficult, it is likely that the two systems do not even agree on what represents the goal of a well-educated engineer. It is no wonder that significant change in engineering education is so difficult.

\section{Second Generation Research to Practice Cycle}

This revised research to practice cycle both derives from the cycles described above and seeks to impact the efficacy with which research to practice cycles occur in engineering education. As seen in Figure 3, we also link the revised research to practice cycle at multiple levels of impact in the engineering education thought systems. Each circle represents the research to practice cycle that occurs at various levels (classroom, institutional, national). Each of these cycles represents its own thought system, with its own founding axioms and constraints. Based on examples such as the Iron Range Engineering (IRE) program that focused curricular and classroom change through implementing project-based learning ${ }^{24,25}$, the organizational infrastructure concerns include issues at the university level, such as the idea of a credit hour, how faculty spend their time, and how is student work transcripted. The initiatives that result in significant change in classroom and curricular practice result in gaps and challenges at institutional, federal and accreditation levels. 


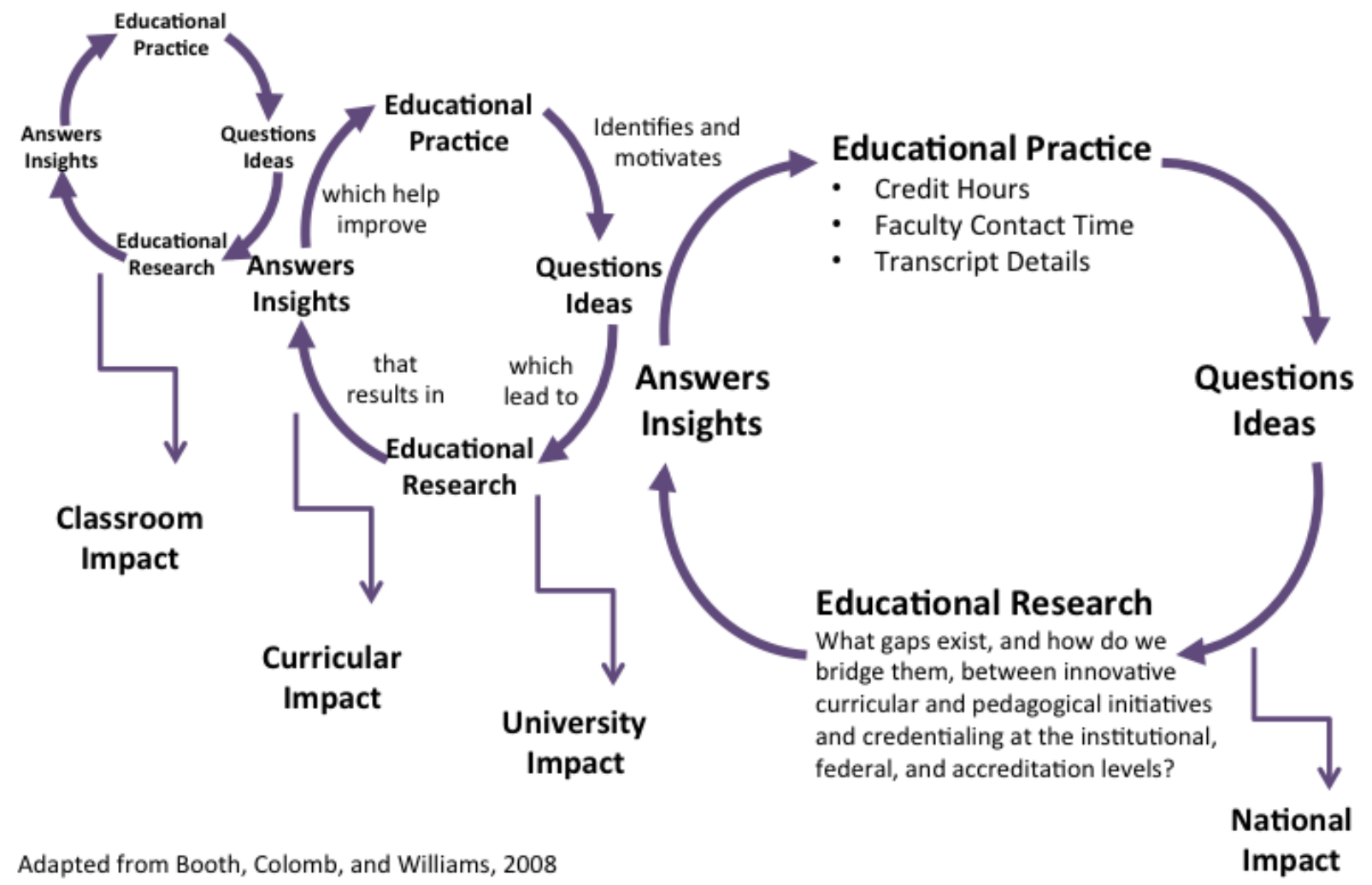

Figure 3. Modified Innovation Cycle of Educational Practice and Research in a Broad Academic Environment

In an ideal system, information and influence would transfer seamlessly across thought systems. In current practice, there are boundaries around the thought systems, illustrated by the boxes in Figure 4 . The thought system that contains multiple calls for changes in engineering education from the national level, such as $26,27,28,29,30,31$, is represented by the lower right box and these ideas must cross the system boundaries to the institutional/college/department box (middle box) and beyond in both directions. The small upper left box represents the thought systems of individual efforts for engineering educational change at the classroom level. These various thought systems have their own founding axioms and system boundaries, but ideas must cross each of these boundaries bi-directionally for effective and sustainable change. Important inhabitants of these thought systems include registrars, unions, ABET, administrators, faculty, students, and others. 


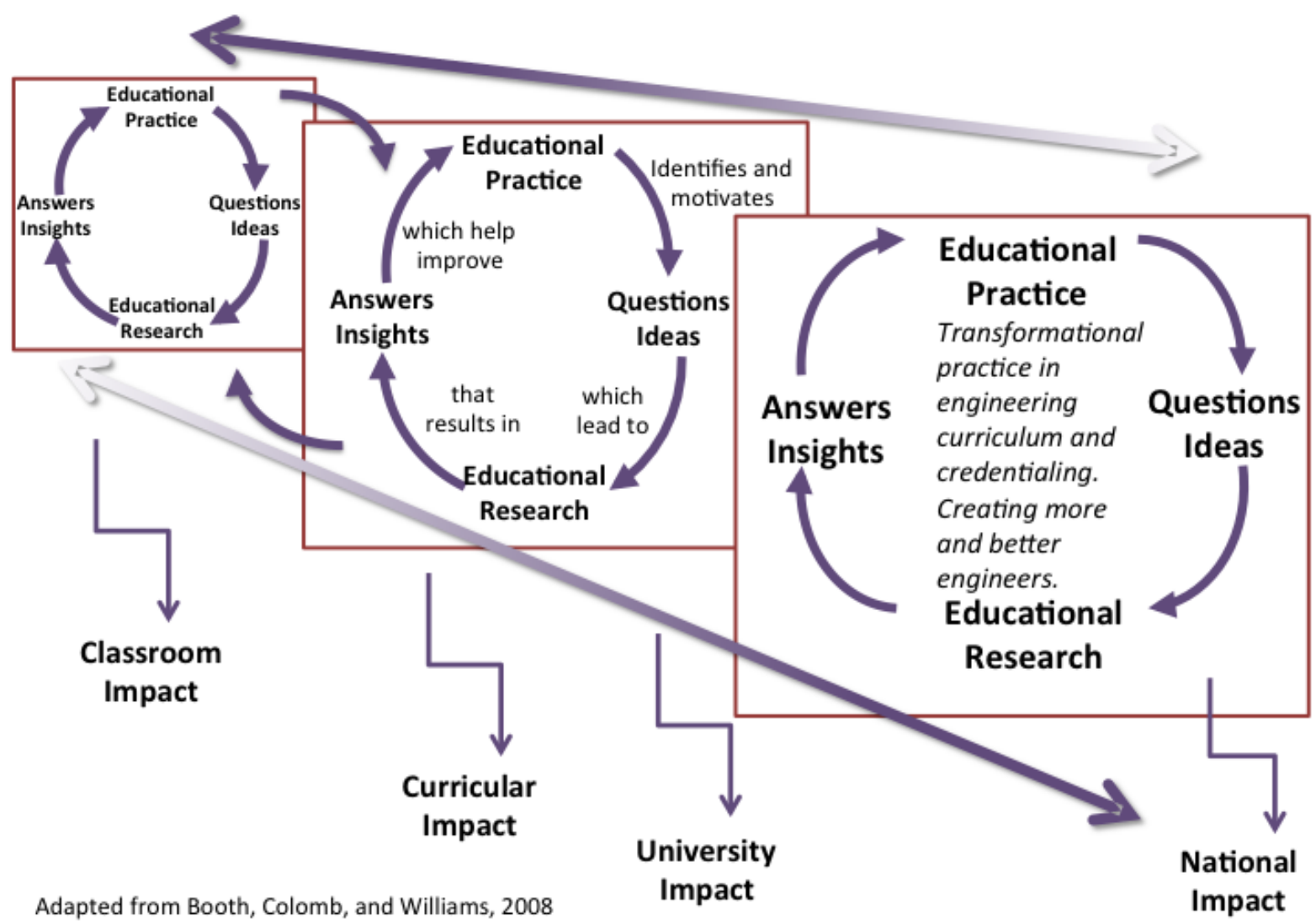

Figure 4. Bridging Innovation Cycles in an Academic Environment Across Thought System Boundaries

In addition to the purely academic pursuit of better educating students, one can also make an economic argument for efficient and effective engineering education change. Emerging economies are producing high numbers of scientists and engineers in comparison to the US. For the US to compete effectively with smaller numbers of scientists and engineers in the innovationbased global economy, it is imperative that the US innovation system be highly efficient. The role the education system can play in this is to develop and produce engineers and scientists with innovative thinking in their "educational DNA". The thought system view proposed herein is a crucial cog in that innovation system gear. Bridging the thought systems from classroom to meeting the national call and from national call to classroom represents the most significant challenge in developing a more efficient and coordinated engineering education system to produce globally competitive innovation.

Expanding the purview of the research-to-practice model will result in better impacts on formal and informal engineering education. Similarly, by starting an inter-disciplinary conversation about how the research-to-practice cycle is accomplished, and how it should be in the future, we can potentially impact the quality and the rate of knowledge transfer in classrooms and to society at large. In order to make sustainable change, we have to interact with the thought systems of the other parts of the engineering education ecosystem. The proposed revised research to practice cycle will allow us to closely examine such interactions from the perspectives of individuals 
based in each of these thought systems. This model will then provide insight into not only how these thought systems interact, but also the fundamental axioms upon which these systems are based and how they operate during organizational change.

\section{Acknowledgements}

This work was supported by the National Science Foundation, award numbers EEC-1439704 and EEC- 1531779.

\section{References}

1. Fairweather, J. (2008). Linking evidence and promising practices in science, technology, engineering, and mathematics (STEM) undergraduate education. Board of Science Education, National Research Council, The National Academies, Washington, DC.

2. Borrego, M., Froyd, J. E., \& Hall, T. S. (2010). Diffusion of engineering education innovations: A survey of awareness and adoption rates in US engineering departments. Journal of Engineering Education, 99(3), 185-207.

3. Prince, M., Borrego, M., Henderson, C., Cutler, S., \& Froyd, J. (2013). Use of researchbased instructional strategies in core chemical engineering courses. Chemical Engineering Education, 47(1), 27-37.

4. Froyd, J. E., Wankat, P. C., \& Smith, K. A. (2012). Five major shifts in 100 years of engineering education. Proceedings of the IEEE, 100 (Special Centennial Issue), 13441360.

5. Jesiek, B. K., Borrego, M., and Beddoes, K. (2010). Advancing global capacity for engineering education research (AGCEER): Relating research to practice, policy, and industry. Journal of Engineering Education, April, 107-119.

6. Stokes, D. (1997) Pasteur's quadrant: Basic science and technological innovation. Washington, DC: Brookings Institutions Press.

7. National Science Foundation. 2007. Course, curriculum, and laboratory improvement (CCLI) (No. NSF 07-543). Arlington, VA. http://www.nsf. gov/pubs/2007/nsf07543/nsf07543.htm (archived document, last accessed, January 2016).

8. Booth, W. C., Colomb, G. G., \& William, J. M. (2008). The Craft Of Research, Chicago Guides To Writing, Editing, And Publishing.

9. ASEE (2009) Creating a Culture for Scholarly and Systematic Innovation in Engineering Education (Phase 1 Report), Washington, DC: American Society for Engineering Education.

10. Schein, E. H. (2010). Organizational Culture and Leadership (Vol. 2). John Wiley \& Sons.

11. Tosti, D. and Herbst, S. A. (2009). Organizational performance and consumer value, Journal of Organizational Behavior Management, 29, 294-314.

12. Dakens, L. (2009). Going beyond best the best-The CN story: An inside look at how CN Rail changed its culture, Canadian HR Reporter. Retrieved October 21, 2015 from http://www.hrreporter.com/articleview/ 7156-going-beyond-best-the-best-the-cn-story.

13. Daft, R. L. (1978). A dual-core model of organizational innovation. Academy of Management Journal, 21(2), 193-210. 
14. Hollen, R. M. A., Van Den Bosch, F. A. J., and Volberda, H. W. (2013). The role of management innovation in enabling technological process innovation: An interorganizational perspective. European Management Review, 10: 35-50.

15. Damanpour, F., Szabat, K. A. and Evan, W. M. (1989). The relationship between types of innovation and organizational performance. Journal of Management Studies, 26: 587602.

16. Smith, W. K., and Tushman, M. L. (2005). Managing strategic contradictions: A top management model for managing innovation streams. Organization Science, 16:5, pp. 522-536.

17. Hargrave, T. J., and De Ven, A. H. (2006). A collective action model of institutional innovation. The Academy of Management Review, 31:4, (2006), pp. 864-888.

18. Karlin, J. (2009). Sub-cultures as leverage for organisational learning and lean thinking. International Journal of Collaborative Enterprise, 1:2, (2009), pp. 147-159.

19. Kluckhohn, C. K. (1949). Mirror for man. New York: McGraw Hill.

20. Redacted for blind review

21. Kolmos, A. and de Graaff, E. (2007). Process of changing to PBL. In Management of Change: Implementation of Problem Based and Project Based Learning in Engineering (pp. 31-45). Rotterdam, The Netherlands: Sense Publishers.

22. Weisstein, Eric W. (A) "Euclid's Postulates." From MathWorld--A Wolfram Web Resource.http://mathworld.wolfram.com/EuclidsPostulates.html

23. Weisstein, Eric W. (B) "Spherical Geometry." From MathWorld--A Wolfram Web Resource.http://mathworld.wolfram.com/SphericalGeometry.html

24. Ulseth, R., Froyd, J., Litzinger, T., Ewert, D., Johnson, B. (2011). A new model of project-based learning in engineering education. Proc. ASEE Annual Conference \& Exposition, June.

25. Ulseth, R. and Johnson, B.(2015). Iron Range Engineering PBL experience. In International Symposium on Project Approaches in Engineering Education (PAEE), 2015. In San Sebastian, Spain.

26. National Academy of Engineering (2004). The Engineer of 2020. Washington D.C.: The National Academies Press.

27. National Academy of Engineering (2005). Educating the Engineer of 2020. Washington D.C.: The National Academies Press.

28. Adams, R. S., \& Felder, R. M. (2008). Reframing professional development: A systems approach to preparing engineering educators to educate tomorrow's engineers. Journal of Engineering Education, 97(3), 239-240.

29. National Science Board (2007). Moving Forward to Improve Engineering Education (p. 1). Arlington, VA: National Science Foundation.

30. Sheppard, S. D., Macatangay, K., Colby, A., and Sullivan, W. M. (2008). Educating Engineers: Designing for the Future of the Field. San Francisco: Jossey-Bass.

31. Duderstadt, J. J. (2008). Higher education in the 21st century: Global imperatives, regional challenges, national responsibilities and emerging opportunities. The Globalization of Higher Education, 195-206. 